\title{
Technology Costs as a Barrier to Energy and Water Efficiency in the Commercial Sector of the United Arab Emirates
}

\author{
Richard Marinshaw, Michael Gallaher, Tanzeed Alam, and Nadia Rouchdy
}

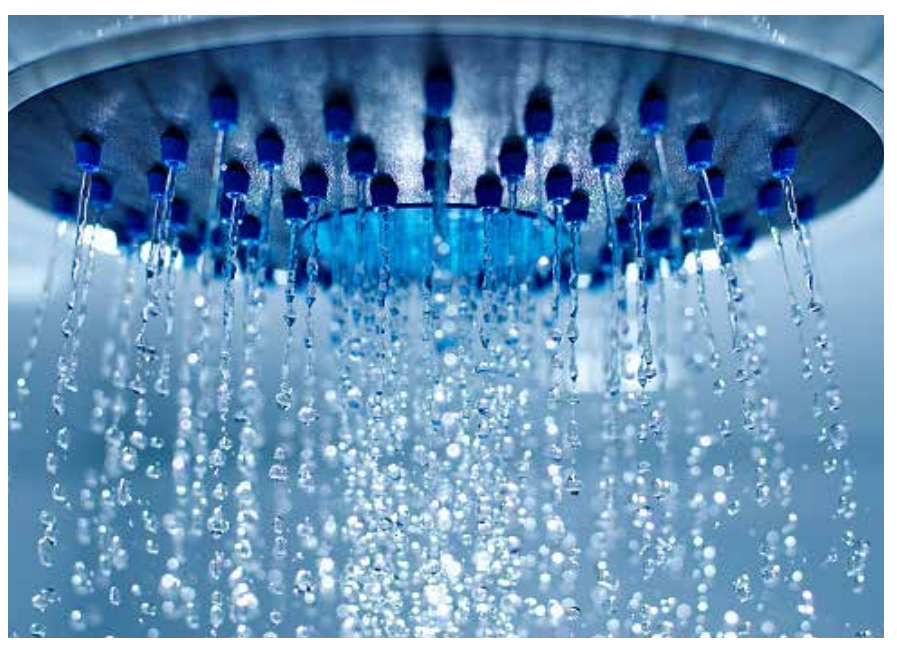

The United Arab Emirates (UAE) is reported to have some of the highest per capita electricity and water consumption rates in the world. For example, in 2014, the UAE was ranked 16th out of 183 countries in terms of kilowatt-hours consumed per capita. ${ }^{1}$ In 2008 , UAE's rate of per capita water consumption was reported to be about twice the rates for the United States and Australia and at least 4 times the rates for three European countries. ${ }^{2}$ Although some of this consumption is a function of the harsh environment and the need for energyintensive cooling throughout most of the year, a significant share is simply because of consumer behavior and inefficient equipment. Consumer behavior, to a large extent, has been

\footnotetext{
This policy brief is a synopsis of a research paper written by the authors and included in the 2016 Emirates Wildlife Society-World Wide Fund for Nature (EWS-WWF) publication Harnessing the Invisible Fuel: How to Unlock Energy and Water Efficiency Potential of the UAE Private Sector (http://uae.panda. org/news/publications/?uNewsID=265910). Reprinted with permission. This brief presents findings from a survey of building energy and water managers in the UAE commercial sector and is intended to inform key stakeholders and motivate government agencies to accelerate tariff reform to promote conservation.
}

driven by the historically low tariffs for both electricity and water. The relative lack of high-efficiency equipment can be attributed to a variety of barriers to adoption, including market barriers, financial barriers, information barriers, institutional and regulatory barriers, and technical barriers. This brief focuses specifically on technology costs as a barrier to the adoption of high-efficiency energy and water technologies and practices in the UAE.

\section{Current Landscape and Barriers}

High-efficiency equipment and technologies are key to reducing the consumption of electricity and water in practically any setting. As a result, the cost of those technologies is a critical factor when making the decision to

\section{Key Policy Implications}

- Technology cost is perceived to be a primary barrier to the adoption of high-efficiency technologies and practices in the UAE.

- A contributing factor is the lack of accurate information on the full range, life-cycle costs, and benefits of high-efficiency products.

- Implementing more stringent codes and standards would help drive demand, stimulate the market for more efficient equipment, and lower costs.

- Enforcing existing standards would help eliminate poor-quality and inefficient products from the market and change the perception that efficient technologies are too expensive.

- Low tariffs and their associated high subsidies distort the costbenefit evaluation of efficient technologies.

- Additional research is needed to understand better to what extent and why technology costs are perceived as such a significant barrier.

- The government can play a greater role in promoting energy and water technology adoption. This will also require cooperation from the private sector to advance initiatives and ensure their implementation. 
switch to high efficiency. In fact, a recent survey conducted by the Emirates Wildlife Society-World Wide Fund for Nature (EWS-WWF) identified technology costs as the most widely reported barrier to implementing efficiency measures in the UAE's commercial sector. ${ }^{3}$ This certainly seems to be a reasonable outcome. One would expect that, although some efficiency products and options are relatively mature and thus cost-efficient, other new or emerging products are likely to cost more as they are introduced to new markets and production processes are refined and optimized. However, studies of both energy and water efficiency measures and programs in Europe, the United States, and elsewhere have found technology costs to be an issue, but findings are mixed as to whether cost has been the primary barrier to adoption. ${ }^{4-7}$ This result raises the question: Is the UAE different in this respect, or do other factors contribute to the conclusion that high-efficiency technologies are too expensive?

A wide range of factors influence the cost and cost-effectiveness of efficient electricity and water technologies. On the benefits side, the most obvious is the cost of electricity and water. If tariff rates embed significant government subsidies, then the monetary savings from investments in efficiency will be marginalized. On the cost side, factors include a lack of information or limited product availability, search and acquisition costs (often referred to as transaction costs), and high purchase prices. In addition, the availability and cost of financing affects overall technology costs. Thus, a bundle of interconnected market barriers impact the perceived cost of efficient technologies.

\section{Technology Costs in the UAE}

To better understand the situation of high-efficiency technology costs in the UAE, the authors investigated two end uses that often are targeted by demand-side management (DSM) programs for reducing electricity consumption: air-conditioning (A/C) and lighting. Replacing an existing A/C unit with a highefficiency model can reduce cooling electricity consumption by more than $40 \% .{ }^{8}$ In terms of electricity consumption, replacing incandescent lighting with compact fluorescent lamps (CFLs) or light-emitting diode (LED) lamps typically reduces electricity usage by more than $75 \% .{ }^{9}$ In both cases, the data indicate the lack of a strong correlation between efficiency and cost.

In 2010, the Emirates Authority for Standards and Metrology (ESMA) implemented a labeling scheme for small A/C units, whereby all units must be labeled with a star rating of 1 to 5 , based on the energy efficiency ratio (EER)-the higher the EER, the higher the star rating. However, data collected by the authors and summarized in Figure 1 show that there is no strong correlation between star rating and unit cost (i.e., cost per ton of cooling). On a per ton basis, the average costs

\section{EWS-WWF Survey}

To understand the barriers to the adoption of energy and water efficiency, EWS-WWF conducted 363 face-to-face interviews with employees in commercial companies tasked with energy and water management. The survey is the first statistically representative survey of the private sector on energy and water efficiency barriers in the UAE. Following the survey, a series of three roundtable meetings were held with a wide range of sector-specific stakeholders from the UAE to gather feedback on the issue papers to enhance understanding of what is required to unleash large-scale energy and water efficiency.

for 1- and 2-star units are less than the average for units with higher star ratings, but some 5-star units cost less than 1- or 2-star units, and the highest average costs are for $\mathrm{A} / \mathrm{C}$ units with a rating of 3 stars. 8

With respect to lighting, a survey of lamps in the Abu Dhabi market found that the unit costs for the most common types of high-efficiency lamps were comparable to the unit costs for incandescent and halogen lamps (see Figure 2). The exceptions were LED lamps, which cost several times as much. ${ }^{8}$ Thus, replacing existing incandescent or halogen lamps with comparable CFLs would be relatively inexpensive.

The relationship between efficiency and cost is less clear for high-efficiency water technologies. Stylishness or appearance is often a significant factor in the selection and cost of water fixtures and appliances, making evaluating how efficiency impacts cost more difficult, which is less true for common electric appliances and fixtures. In terms of lifetime, water fixtures are much more durable and do not have to be replaced as often as lighting or $\mathrm{A} / \mathrm{C}$ units. For example, faucets and toilets typically last more than 20 years, compared with 8 to 12 years for $\mathrm{A} / \mathrm{C}$ units and only a few years for lighting. Thus, for these water fixtures, there are less-frequent end-of-life decision points that provide the opportunity to upgrade to high-efficiency models, which can save $40 \%$ to $80 \%$ in water consumption.10,11

The faucet aerator is an exception among these examples. Aerators are simple devices, which cost a fraction of what a new faucet would cost, and when inserted into the spout of a faucet, reduce the flow rate by about $15 \%$. Although there have been campaigns in the UAE to install aerators in existing fixtures, there are no indications that this technology is in widespread use or has been readily adopted by the commercial sector.

This lack of correlation between cost and efficiency is not unique to the UAE; research by the International Energy Agency found that, for many high-efficiency technologies, price and efficiency have little correlation because different volumes of production lead to differences in economies of scale and, 
Figure 1. Small A/C unit cost, by ESMA star rating

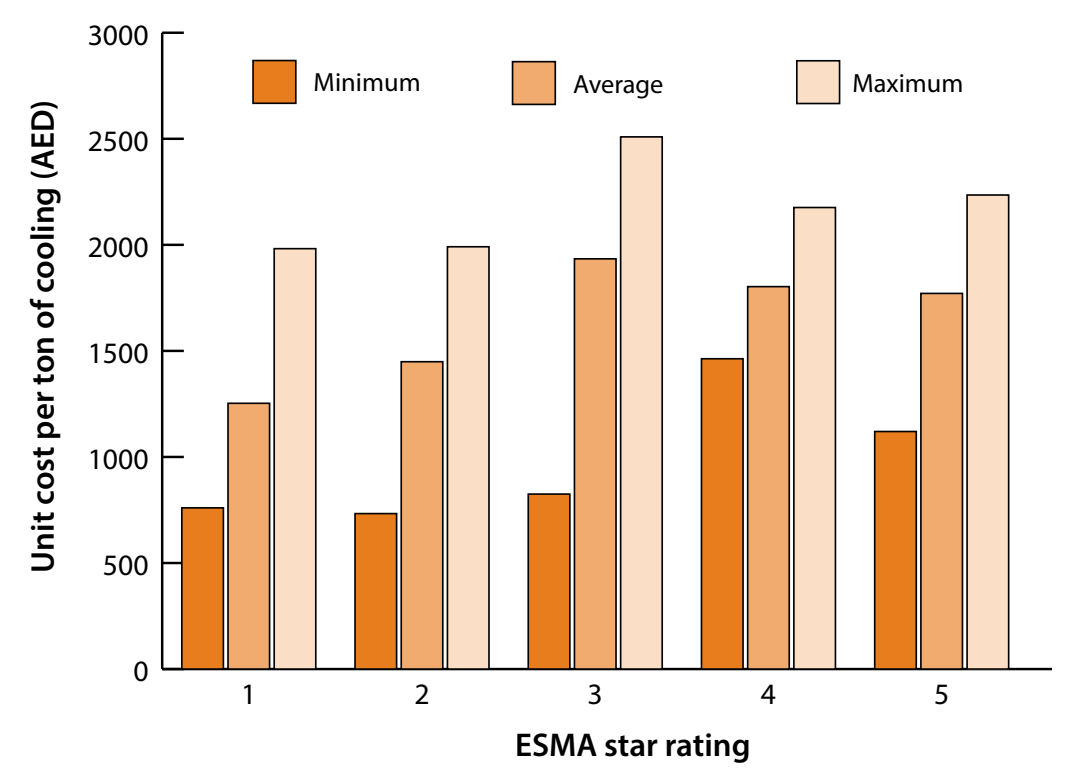

Figure 2. 2012 Abu Dhabi lighting survey

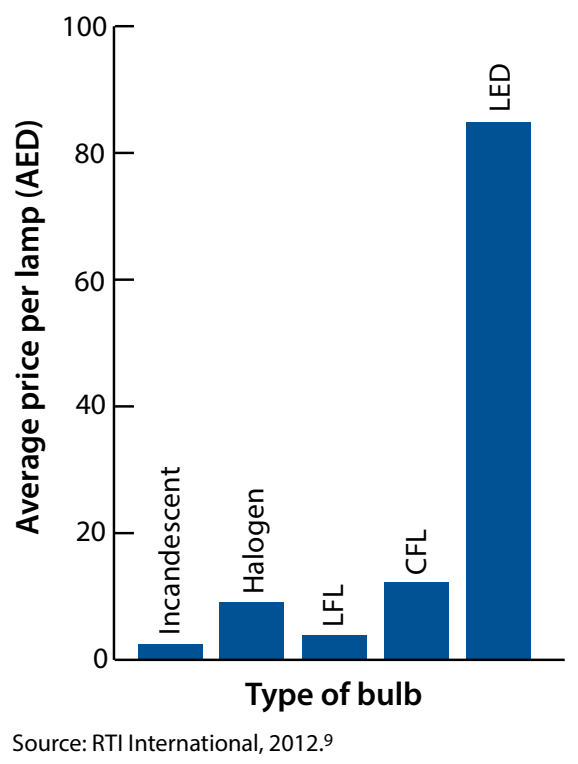

Source: RTI International, 2016.8

hence, cost. 12 However, more analysis is needed before it can be concluded that this is the case for high-efficiency technologies in the UAE. When compared with the situation in Europe and North America, the UAE is a relatively small market, and smaller markets can lead to higher technology costs in two ways: first, fewer options for high-efficiency technologies means less competition to drive prices lower; second, smaller markets preclude having the economies of scale that can bring prices down. In addition, the demand for efficient technologies is in large part driven by equipment and building standards that mandate conservation. Although codes and standards incorporate efficiency criteria in the UAE, the mandates are a fairly recent development, and many target new construction rather than existing buildings. Thus, there is not a long history of adoption that would promote a larger, more competitive market for such technologies.

\section{Other Factors That Affect Perceived Technology Costs}

Although the survey results did not pursue the details of why respondents concluded that technology costs were a significant barrier to high-efficiency energy and water technology adoption, the respondents may have viewed costs much more broadly than simply the purchase price of high-efficiency retrofit products. For example, respondents may have included transaction costs, which encompass the costs for researching the technology, getting company approval, and following up (e.g., verifying the savings achieved). The lack of capital or the high cost of financing may also have factored into how respondents defined technology costs. Finally, the value of electricity and water savings depends on the tariff rate, and both utilities have been heavily subsided in the UAE.

\section{Opportunities and Solutions}

As part of the EWS-WWF survey, participants were asked to identify possible solutions to overcoming those barriers. Most of the solutions identified relate to either financing or the lack of information on technologies. In terms of financing, survey respondents suggested equipment discounts, price limits, and product rebates to reduce technology costs. With operational discounts, companies would receive credits for having invested in efficient technologies. Price limits would likely involve subsidies or rebates going to suppliers. Product rebates to consumers are a proven solution to increasing adoption of efficient technologies and have been a hallmark of DSM programs in the United States and elsewhere by offsetting the initial purchase price of high-efficiency fixtures and appliances.

A theme that seems to pervade the survey results on technology costs is the lack of adequate information on high-efficiency technologies. Without information on installation costs, availability, compatibility, life expectancy, and maintenance costs, it is difficult to make an informed decision on whether a high-efficiency technology is cost-effective.

Other potential solutions include tariff reform, increasing market availability, implementing more stringent codes and standards, adding options for financing, and other government interventions. Although tariff reform does not directly affect technology costs, higher tariffs improve the overall economics of adoption by increasing the value of the savings achieved. The availability of high-efficiency products in the marketplace plays an important role in adoption by raising awareness, reducing the time and effort associated with searching for highefficiency options, and increasing competition, all of which 
help lower costs. More stringent and stricter enforcement of codes and standards would also help the adoption of highefficiency technologies by minimizing the incremental cost to the commercial sector. Installing efficient technologies at the time of construction is always less costly and would help build demand, which could further drive down costs because of economies of scale.

The commercial sector would benefit from increased availability of loans to help finance the adoption of high-efficiency technologies. Although this may not have an immediate effect on technology costs, it would help promote adoption and increase demand for high-efficiency technologies, and therefore help mature the market, rendering these technologies more affordable over time. The government could also ease the barriers associated with technology costs by creating a program to retrofit high-efficiency products in federal buildings, which could generate a sizable market demand for such products because government agencies control a significant portion of the economy and, hence, a large share of office buildings.

\section{Conclusion}

The survey conducted by the EWS-WWF identified technology costs as the top barrier to adopting high-efficiency energy and water technologies in the UAE. A contributing factor to the perception that efficient technologies may not be affordable is the lack of accurate information on the full range and life-cycle costs and benefits of high-efficiency products. Similarly, the solutions for eliminating the technology cost barrier, as identified by survey participants, would be to address the financing and informational aspects of the barrier and potentially provide direct incentives such as rebates. In addition, it is essential that attention be given to the broader suite of barriers underlying the technology cost issue, such as subsidized tariffs, relatively few standards for energy- or waterefficient equipment, and limited enforcement of existing codes and standards.

The following actions would contribute significantly to eliminating the cost barrier and promoting the adoption of high-efficiency technologies in the UAE:

- Develop strong standards and labels that drive demand and stimulate the supply market, improve economies of scale, and lower costs.

- Enforce existing standards to eliminate from the market poor-quality and inefficient products that tend to distort customer perception of technology costs.

- Raise tariffs, which would improve the cost-benefit evaluation of efficient technologies and lead to a change in the perception of technology costs.
- Conduct additional research to better understand to what extent and why technology costs are perceived as such a significant barrier to efficient technology adoption.

\section{References}

1. The World Bank. Electric power consumption (kWh) for the year 2014. Washington, DC: World Bank; 2016. Available from: http://data.worldbank.org/indicator/EG.USE. ELEC.KH.PC

2. Regulation and Supervision Bureau. Consumption: water and electricity consumption by residential customers. Abu Dhabi, UAE: Regulation and Supervision Bureau; 2008.

3. Emirates Wildlife Society-World Wildlife Fund (EWS-WWF). Energy and water efficiency in the UAE: an exploration of the top three private sector barriers. Dubai, UAE: EWS-WWF; 2016.

4. Fleiter T, Schleich J, Ravivanpong P. Adoption of energy-efficiency measures in SMEsan empirical analysis based on energy audit data. Energy Policy. 2012;51:863-75.

5. Department of Energy \& Climate Change (DECC). International research to assess the barriers and drivers to energy efficiency in small and medium sized enterprises. London, England: DECC; 2014.

6. Washington State Department of Ecology (WSDE). Actions and progress on water useefficiency. Report to the legislature. Olympia, WA: WSDE; 2003.

7. A \& N Technical Services (A\&N). Urban water conservation: implementation challenges and opportunities. Prepared for California Urban Water Agencies. Encinitas, CA: A\&N; 2004.

8. RTI International. Non-chiller A/C unit repair, maintenance, and replacement pilot project, final report. Prepared for Abu Dhabi Executive Affairs Authority. Research Triangle Park, NC: RTI International; 2016.

9. RTI International. Development of residential lighting standards for the United Arab Emirates, baseline assessment, final report. Prepared for Emirates Wildlife Society in association with the World Wide Fund for Nature. Research Triangle Park, NC: RTI International; 2012.

10. RTI International. Demand-side management for electricity and water use in Abu Dhabi. Research Triangle Park, NC: RTI International; 2009.

11. Abu Dhabi Quality Conformity Council. Abu Dhabi certification scheme for efficient water fixtures, assessment and surveillance plan. Abu Dhabi, UAE: Abu Dhabi Quality Conformity Council; 2014.

12. International Energy Agency (IEA). Experience with energy efficiency regulations for electrical equipment. Paris, France: IEA; 2007.

\section{About the Authors}

Richard Marinshaw is a senior research environmental engineer in RTI International's Sustainable Business Solutions Division.

Michael P. Gallaher, PhD, is the senior director of RTI's Center for Environmental, Technology, and Energy Economics.

Tanzeed Alam, MSc, is the climate and energy director at EWS-WWF in the United Arab Emirates.

Nadia Rouchdy, BCom, is a manager for climate change and energy at EWS-WWF in the United Arab Emirates.

\footnotetext{
RTI Press Research Briefs and Policy Briefs are scholarly essays on policy, methods, or other topics relevant to RTI areas of research or technical focus.

RTI International, 3040 East Cornwallis Road, PO Box 12194 Research Triangle Park, NC 27709-2194 USA

$+1.919 .541 .6000 \quad$ rtipress@rti.org www.rti.org

C2017 RTI International. All rights reserved. Credit must be provided to the author and source of the publication when the content is quoted. No part of this publication may be reproduced in any form by any electronic or mechanical means without permission in writing from the publisher. RTI International is a registered trademark and a trade name of Research Triangle Institute.

www.rti.org/rtipress
} 